\title{
Fault activity studies in the Lower Tagus valley and Lisbon region using geophysical data
}

\author{
João Carvalho'*, Ranajit Ghose², José Borges³, Daniela Alves'1,4, Elsa Ramalho' and \\ Jaime Leote' discuss the near surface geophysical (mainly seismic reflection) results that, \\ taken together with borehole data, strongly suggest that these faults have had activity in \\ the Holocene and were probably the source of some historical earthquakes.
}

\section{Introduction}

The Metropolitan Area of Lisbon and the Lower Tagus Valley (LTV) region are located in central Portugal and inhabited by nearly 4 million people. The region has suffered throughout its history the effect of destructive earthquakes caused by hidden faults, possibly related to the plate boundary, which is sited approximately $400 \mathrm{~km}$ south of the region (Figure 1). In spite of low slip-rates and big recurrence times that have been estimated for these local, regional faults, they can produce moderate-to-large earthquakes that cause large damage and loss of life, as in 1344, 1531, or 1909 (e.g. Justo and Salwa, 1998; Cabral et al., 2003; 2013). The shorter occurrence time of the earthquakes might be owing to the existence of multiple active faults and/or time clustering owing to stress drop caused by proximal faults (e.g. Carvalho et al., 2006). Therefore, the

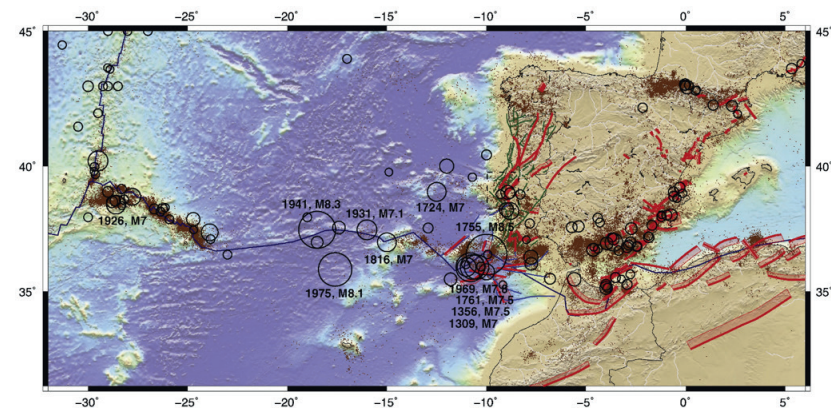

Figure 1 Seismotectonic of the Azores-Iberia region (after Custódio et al., 2016 and references therein), where the study area is included (dashed square). Earthquakes recorded instrumentally since 1996 are shown by small brown dots. Historical earthquakes reported by the SHARE European Earthquake Catalogue - SHEEC - with magnitudes larger than 5.5 are shown by circles with a radius corresponding to the earthquake magnitude (Stucchi et al., 2013). The earthquakes with magnitudes equal to or larger than 7.0 are labelled with year of occurrence and magnitude. The plate boundaries of the global plate tectonics NNR-MORVEL56 model are shown by dark-blue lines (DeMets et al., 2010; Argus et al., 2011). The surface projection of potentially active faults compiled on the SHARE database are shown by red rectangles, the surface trace of the faults is marked by a thick red line (Basili et al., 2013; Vilanova et al., 2014). The SHARE faults in western Iberia are underlain by the original fault traces proposed by Cabral (2012) (green) and Duarte et al. (2013) (blue). The topography in the background is taken from the global SRTM30+ model, obtained from satellite altimetry and ship depth soundings (Smith and Sandwell, 1997; Becker et al., 2009). seismic hazard and risk evaluation of the region has long been a reason of concern.

Geological outcrop and geomorphologic mapping identified several regional faults in the LTV region that could be the source of the historical earthquakes, but some of them do not affect Quaternary sediments and lacked the proofs that they were active faults. On the other side, in the vast quaternary alluvial plains that cover the region, it was difficult to identify active faults, as the sedimentation/erosion rates erase any possible surface rupture caused by the low slip-rate faults $(<0,35 \mathrm{~mm} / \mathrm{y})$. By the late- $20^{\text {th }}$ century, seismic reflection data that had been acquired for the oil-industry till the beginning of the 1980 s began to be used to identify the major hidden fault zones (e.g. Cabral et al., 2003; Vilanova and Fonseca, 2004; Carvalho et al., 2006). Potential field data was also used to locate active faults in the areas where no seismic data is available (Carvalho et al., 2008; 2011). Though a few more active faults have been proposed, the vast majority of authors agree that the following active faults threaten the region: Nazaré-Caldas da Rainha, Lower Tagus Valley, Ota, Azambuja, Vila Franca de Xira (VFX), Pinhal Novo and Porto Alto faults (Garcia-Mayordomo et al., 2012; Vilanova et al., 2014).

In this work, we discuss the acquisition, processing and interpretation of near surface geophysical works carried out over three of these faults - the VFX, Porto Alto and Azambuja faults - in order to confirm they have had activity during the Holoceneera. Their location is shown in Figure 2. We further estimate some of its fault parameters (vertical displacement, slip-rate, length, etc.) and respective implications in terms of seismic hazard.

Traveltime tomography or ground penetrating radar (GPR) are often used to study shallow faults. However, GPR has depth penetration problems in clayey environments with a shallow water table, such as in some parts of the study area. Travel time tomography could be an alternative but in an area of soft sediments with a high water content and ductile behaviour, the velocity contrast between the fault planes and the adjacent sediments is expected to be low $(<20 \mathrm{~m} / \mathrm{s})$ and insufficient for an adequate tomographic mapping. Seismic reflection is commonly used to investigate shallow fault zones (e.g., Woolery et al., 1993;

' Laboratório Nacional de Energia e Geologia, Portugal | ${ }^{2}$ Delft University of Technology

${ }^{3}$ Instituto de Ciências da Terra, University of Évora, Portugal | ${ }^{4}$ Presently at Randstad

Corresponding author, E-mail: joao.carvalho@Ineg.pt 


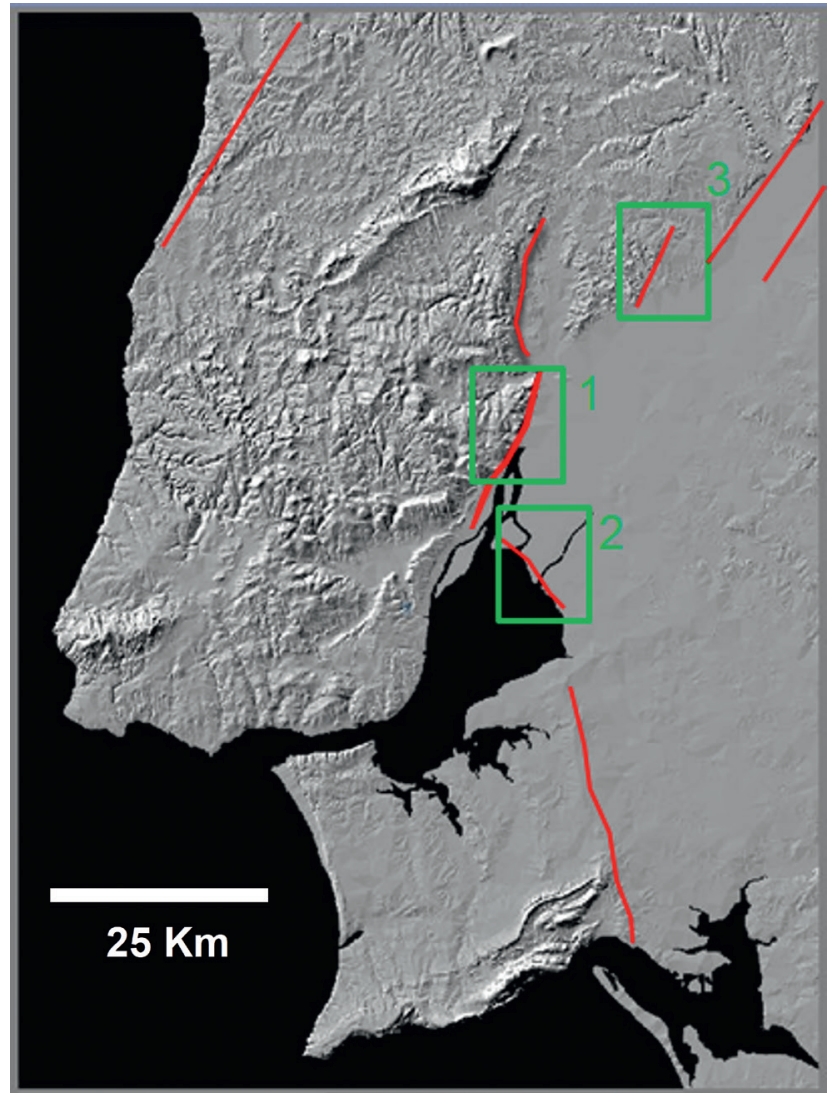

Figure 2 a) Location of the active faults in the study area according to the SHARE (Vilanova et al., 2014) and Quafi (Garcia-Mayordomo et al., 2012) databases and the faults studied in this work (surrounded by rectangles). 1- Vila Franca de Xira Fault (VFX fault), 2- Porto Alto fault and 3-Azambuja fault.

Benson and Mustoe, 1995; Floyd et al., 2001; Wang et al., 2004; Harris, 2009; Campbell et al., 2010), as it offers a good resolution and works in most geological situations. In particular, for soft soils, S-waves generally have a higher resolution than P-waves and a greater sensitivity to the subtle changes in the soil-type or composition (e.g., Brouwer et al., 1997; Ghose and Goudswaard, 2004; Ghose, 2012) and was therefore the preferred method. To corroborate the results, GPR was also broadly used and in some areas, geoelectric methods (dipole-dipole configuration).

\section{Vila Franca de Xira fault}

The VFX fault is located about $25 \mathrm{~km}$ northeast of the densely populated central Lisbon. Based on isoseismal data, the VFX fault was thought to have been active through the Quaternary and the source of multiple damaging earthquakes that affected Lisbon and neighbouring cities, as in 1344 (e.g. Cabral et al., 2003), 1531 (Justo and Salwa, 1998), 1807 (Vervaeck et al., 2011) and 1909 (Cabral et al., 2013).

In spite of this, the fault was only seen in outcrop to affect Miocene sediments and no proof of fault activity in the Quaternary had been found. Oil-industry P-wave seismic reflection data interpretation supported by borehole data suggested that the fault was present beneath the alluvial cover (Carvalho et al., 2006) but the limited vertical resolution (2-3 m) prevented us from confirming if the fault affected Holocene sediments. After a first P-wave profile was acquired in 2000 close to VFX city to confirm the presence of the VFX beneath the alluvial cover (Carvalho et al., 2006), a second profile located about $2 \mathrm{~km} \mathrm{NE}$ near Castanheira do Ribatejo (CDR) was acquired in 2010 to check if a second fault zone could be detected at a location compatible with the trend of the VFX. Data processing and its interpretation showed a major fault zone at the expected location, and shortly after, a GPR profile was acquired over the P-wave profile and at a third location confirming the presence of the VFX fault zone beneath the alluvial cover. As stated above, S-wave seismic reflection could offer superior resolution in these type of soils (Ghose and Goudswaard, 2004) as could GPR, if enough penetration could be achieved. Therefore, in 2009 and 2012, S-wave reflection profiles were acquired at two sites, VFX and Castanheira do Ribatejo (CDR). S-wave data offered a resolution of 0.3-0.4 m and strongly suggested deformation and several fault branches affecting holocene water-saturated sediments. In Figure 3 we show the stacked section of one of the S-wave profiles (VFX), together with horizon velocity analysis for several reflectors and a few shot gathers. The systematic integration of multiple evidences of faulting-related deformation in sediments following the approach of Ghose et al. (2013), indicated the presence of fault branches affecting the shallow surface. According to boreholes drilled for geotechnical and water supply purposes, alluvium reaches a thickness of 50-60 m at the CDR location and about $25 \mathrm{~m}$ at the VFX site and, therefore, the alluvial cover is deformed by the fault branches. To corroborate the results at the CDR site, dipole-dipole surveys were carried out at the locations where the fault approached the surface. Discontinuities in the geolectric profiles were found at coincident locations with the fault branches interpreted in the seismic data.

In the spring of 2013, three trenches were opened at the CDR site, to date the fault activity with more precision. However, no more than $5 \mathrm{~m}$ could be opened revealing homogenous, dark, water-saturated clays, in agreement with seismic results that showed no reflector until a depth of about $10 \mathrm{~m}$.

$2 \mathrm{D}$ visco-elastic modeling was then performed, which suggested a vertical displacement of about $3 \mathrm{~m}$ at the base of the
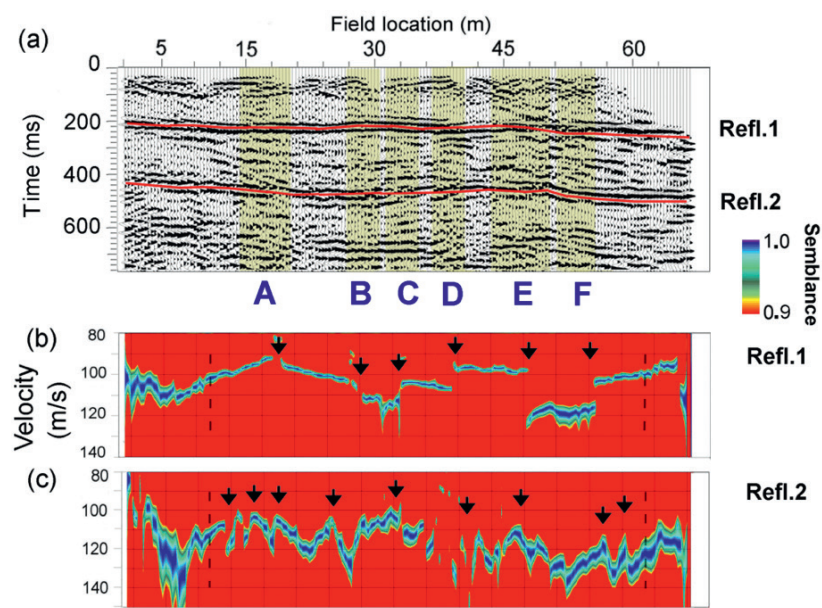

Refl.1

Figure 3 (a) Migrated (bottom) S-wave stacked time section at Vila Franca de Xira. The main reflections horizons (Refl.1, Refl.2) in this area are verified in independent borehole measurements. (b) Horizontal velocity analysis (HOVA) of reflection event 1 (c) HOVA analysis for reflection event 2. Arrows indicate position of fault segments (A to F) also observed at coincident locations in shot gathers and stacked section. 


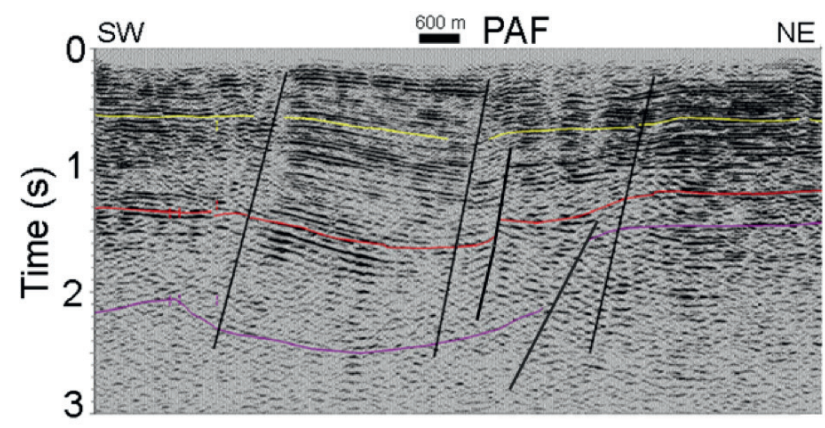

Figure 4 Oil-industry P-wave seismic stacked section showing the Porto Alto Fault (PAF) and other faults (black lines). Yellow line: top of Miocene; Red line: top of Mesozoic; Purple line: top of Hettangian and older rocks.

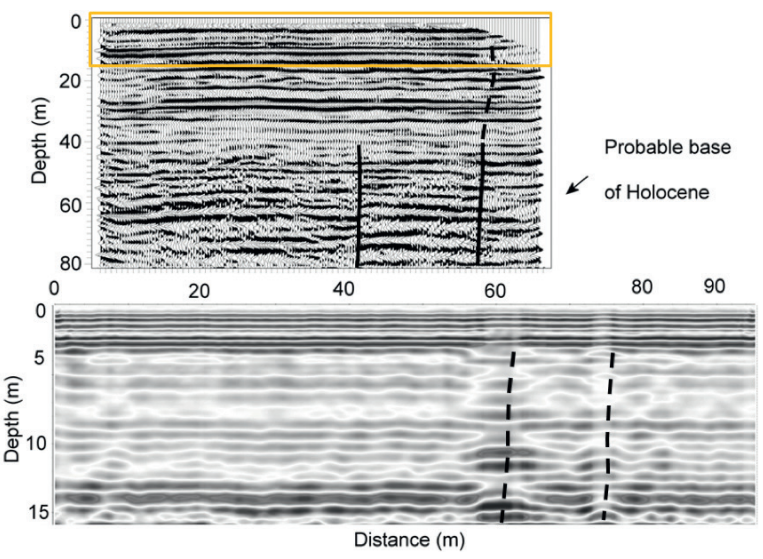

Figure 5 Top: depth converted S-wave stacked section using processing velocities, where shallow fault branches of the Porto Alto Fault have been interpreted. Arrow point to the base of the Holocene alluvium, suggesting recent fault activity. Rectangle indicates samples of the GPR profile. Bottom: coincident GPR profile where two possible fault branches have been interpreted, one of them coincident with the S-wave section shown above.

$14 \mathrm{Ky}$ aged alluvium, and several seismogenic parameters were estimated based on the geophysical interpretation.

\section{Porto Alto Fault}

The Porto Alto fault zone is a regional, WNW-ESE oriented structure, possibly linked to the Pinhal Novo fault with a major strike-slip component which is clearly visible in oil industry P-wave data (Figure 4). Again, the upper $50 \mathrm{~m}$ that corresponds to the holocene alluvium cover are poorly imaged owing to the acquisition geometry used. Therefore, a site close to Porto
Alto was chosen for acquiring high-resolution P-wave seismic reflection and vertical electrical soundings data (Carvalho et al., 2006) in order to locate the fault zone. The fault was imaged but the lack of resolution in the holocene sediments to resolve a fault of maximum 1-2 m anticipated vertical throw was evident even in the shallow high-resolution P-wave dataset (with about 2-3 m of vertical resolution).

The area where the shallowest fault segments were observed were the target of S-wave and GPR data that was planned to be imaged at the middle of the sections. Both shear wave and GPR data were acquired over a hard, non-paved road crossing the flat, alluvial plain. A second S-wave profile was acquired parallel to the first, over the alluvial plane. Data processing and interpretation of both datasets led to the results shown in Figure 5, where three fault segments are interpreted to affect the alluvial cover until a depth of $5 \mathrm{~m}$. Owing to a very shallow water table $(1 \mathrm{~m})$ and sediments plasticity, it is not feasible to open a trench and image the fault. Two seismic cone penetration test boreholes (SCPT) were drilled over the S-wave and GPR profiles, one at the centre of the S-wave profile and the second at the southern end. As expected, the results do not show direct evidence of the fault segments, owing to lateral facies changes typical of fluvial environments, the sediments ductility and the expected small vertical throw of the fault (1-2 $\mathrm{m}$ is the typical vertical throw in the Holocene for these low slip-rate faults). However, the SCPT did show that the depth of the alluvium is greater than the $30 \mathrm{~m}$ reached by the boreholes, meaning that the imaged fault segments affect the $20 \mathrm{k}$ aged sediments.

\section{Azambuja fault}

The Azambuja fault is a NNE oriented structure, with a clear morphological signature, where Miocene and Pliocene sediments are tilted eastwards and offset by steeply dipping mesoscale faults presenting reverse and normal offsets with a net downthrow to the east. It is considered to be an active fault (Cabral et al., 2003; 2004) and neotectonic studies indicate the Quaternary slip on the fault to be in the range $0.05-0.06 \mathrm{~mm} / \mathrm{year}$, but its activity in the Holocene has not been established so far.

With this goal in mind, a strategy similar to one adopted at the other faults sites was initiated: a longer P-wave profile to locate the fault zone beneath the alluvial cover followed by acquisition of S-wave seismic profiles at selected areas where the fault segments come closer to the surface. The profiles were located very
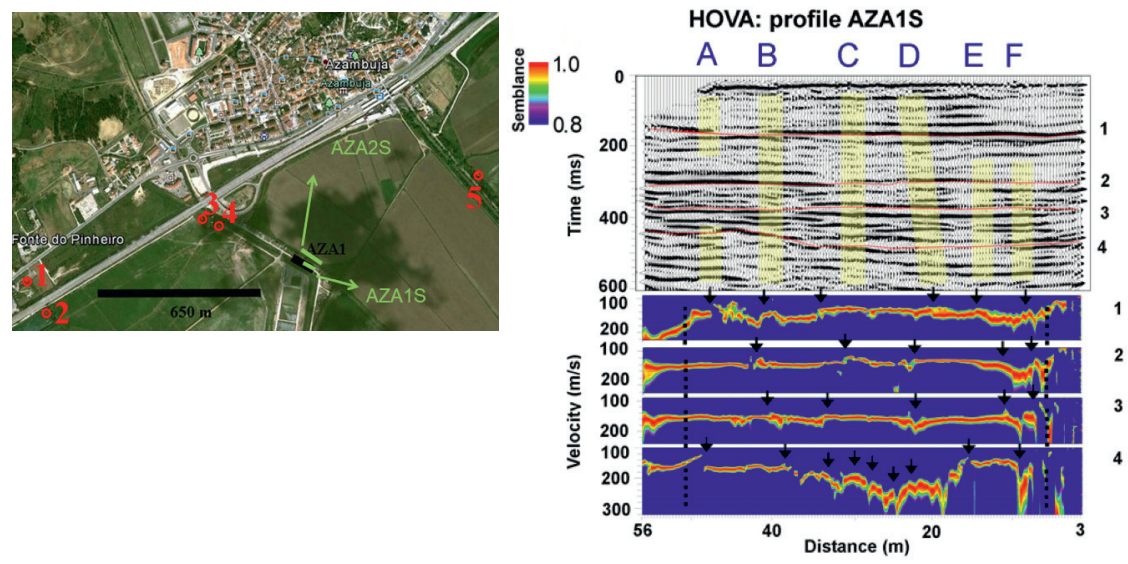

Figure 6 Far left: Google Earth image showing the location of seismic reflection profiles that have been acquired to locate and image the Azambuja Fault, south of the city. P-wave (AZAI) and S-wave (AZAIS and AZA2S) have been acquired. Boreholes used to establish the base of Holocene alluvium are shown as circles. Top left: S-wave stacked section AZA1S where several fault branches were identified. Letters $A$ to $E$ and yellow-shaded areas indicate these locations. Red lines indicate seismic reflective events for which horizontal velocity analysis (HOVA) has been performed, shown below the stacked section. Arrows point to velocity lows/ jumps spatially coincident with disturbances in the shot gathers and stacked sections. 

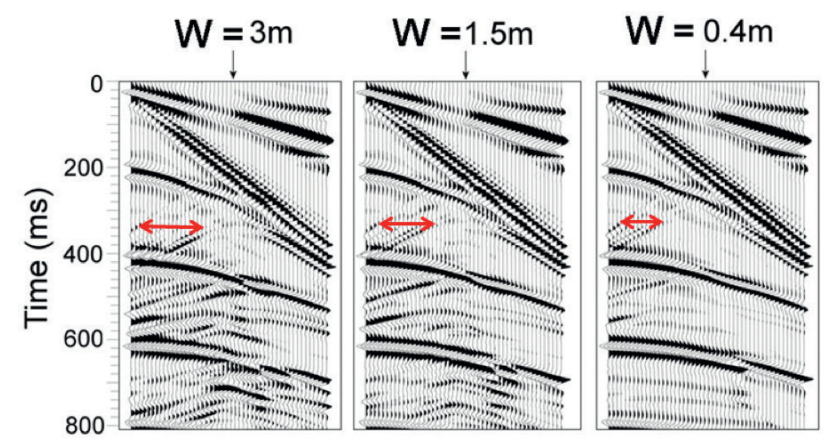

Figure 7 Synthetic shot gathers produced with 2D forward elastic modelling code (Thorbecke and Draganov, 2011) for the VFX data, using a velocity model obtained from the processing velocities and borehole data. For simplicity, a single fault was inserted in the velocity model and the same shot gather is shown for different widths of this fault (W). Double sided arrows point to back-scattered reflection from both sides of the fault segment, showing that it is possible to estimate fault width by comparison with field gathers

close to the southwestern tip of the fault outcrop, over the alluvial plain. A first S-wave profile was acquired over the $100 \mathrm{~m}$-long $\mathrm{P}$-wave line and a second S-wave profile was acquired parallel to the first. Boreholes available several hundred metres from both ends of the P-wave profile, showed that the base of the alluvium rests at depths of 30 and $22 \mathrm{~m}$ at the east and west of the profile, respectively. The location of the boreholes with regard to the seismic profiles is shown in Figure 6.

The S-wave stacked section coincident with the P-wave profile is shown in Figure 6. Following the methodology of Ghose et al. (2013), we performed the analysis of the shot gathers and the horizon velocity analysis (HOVA) for several reflectors to check the location of possible fault branches. These are also shown in Figure 6. Finally, 2D visco-elastic modelling using a finite difference code (Thorbecke and Draganov, 2011) was performed to corroborate our interpretation. In spite of the simple modelling carried out, a good resemblance between synthetic and field shot gathers was achieved. Several modelling tests suggest that the near absence of back-scattered energy from the fault segments, observed in the VFX and CDR sites, can be explained by the existence of multiple reflectors and a stronger attenuation when compared to the other sites. A pebble layer detected at the Azambuja boreholes at approximately $12 \mathrm{~m}$ depth and around 30 $\mathrm{m}$ at CDR and VFX sites is probably the cause of the increased attenuation.

\section{Estimating fault parameters in the region}

In the study area, often it is not possible to open trenches owing to a shallow water table, the plasticity of the sediments or a geologically homogeneous near surface. Drilling boreholes is also difficult, not only because of engineering structures but because land owners do not give permission. The estimation of fault vertical throw and related fault parameters as co-seismic rupture or slip rate has to be based on geophysical interpretations.

For this purpose, we have performed elastic and visco-elastic 2D modelling (Thorbecke and Draganov, 2011) of shot gathers and stacked sections. By varying distinct fault parameters such as fault vertical throw, fault width, velocity contrast inside fault segments with adjacent sediments, etc. and comparing them with field shot gathers it is possible to estimate true faults parameters. In Figure 7 an example is shown from the VFX Fault zone of how fault segment width can be estimated from S-wave seismic data. Arrows indicate separation of back-scattered energy from both sides of a fault segment, for different fault segment widths (W in Figure 7)) and a fixed velocity contrast with adjacent sediments based on HOVA analysis. By comparing synthetic gather with the field we estimate a fault segment width of $0.4 \mathrm{~m}$, similar to other outcropping fault segments observed in other areas of Iberia (e.g. Rockwell et al., 2009; Perea et al., 2003)

\section{Conclusions}

Compared to the detection of faulting-induced major displacements of geological boundaries, the detection of ductile, soft-sediment deformation with small vertical throw $(<1 \mathrm{~m})$ or damaged zones in soil owing to earthquake-induced ground shaking is more difficult to detect with shallow seismic reflection or other geophysical data, owing to resolution issues.

It was found that, for recognizing and interpreting the presence of such disturbances in the shallow seismic reflection data, identification of multiple evidences in the data and their confirmation through simple but careful forward modelling leads to an effective and reliable exploration approach. The use of S-waves in the unconsolidated soil is advantageous not only because of the high resolution owing to the low velocity of S-waves in soft soils, but also because of the high-sensitivity of S-waves to subtle changes in the soil.

Using six different (but related) evidences of soft-sediment deformation in the shallow S-wave reflection data at three distinct fault zones in Portugal, Vila Franca de Xira, Porto Alto and Azambuja it is shown, with the aid of borehole data, that these faults have caused activity in the Holocene. To corroborate the interpretation, forward viscoelastic modelling was performed and the comparison between field and synthetic shot gathers allowed to confirm that these are indeed active faults and very probably the cause of historical seismicity. Preliminary modelling results show that it is possible to infer some fault parameters from these data, such as fault width and geometry, vertical throw and slip-rates.

\section{Acknowledgements}

The authors are grateful to the Portuguese Foundation for Science and Technology for financing projects NEFITAG-PTDC/CTEGIX/102245/2008, ATESTA-PTDC/CTE-GIX/099548/2008 and SISMOD/LISMOT-PTDC/CTE-GIN/82704/2006, under which seismic data was acquired. Bento Caldeira, principal investigator of the ATESTA project, is especially acknowledged. The help in the fieldwork by Fernando Caneiras is greatly appreciated. We are indebted to João Palha, João Lopes, Companhia das Lezírias, the landowners of the VFX, CDR, Porto Alto and Azambuja sites, respectively.

\section{References}

Benson, A.K. and Mustoe, N.B. [1995]. Analyzing shallow faulting at a site in the Wasatch fault zone, Utah, USA, by integrating seismic, gravity, magnetic, and trench data. Eng. Geol., 40 (3-4), 139-156.

Brouwer, J., Ghose, R., Helbig, K. and Nijhof, V. [1997]. The improvement of geotechnical subsurface models through the application 
of S-wave reflection seismic exploration. Proc. Eng. and Environ. Geophys. Eur. Sec. Meeting, Aarhus, 103-106.

Campbell, F.M., Ghisetti, F., Kaiser, A.E., Green, A.G., Horstmeyer, H. and Gorman, A.R. [2010]. Structure and evolution of the seismically active Ostler Fault Zone (New Zealand) based on interpretations of multiple high resolution seismic reflection profiles. Tectonophysics, 495 (3-4), 195-212.

Cabral, J., C. Moniz, J. Batló, P. Figueiredo, J. Carvalho, L. Matias, P. Teves-Costa, R. Dias and N. Simão [2013]. The 1909 Benavente (Portugal) earthquake: search for the source. Natural Hazards, 69, 1211-1227. DOI 10.1007/s11069-011-0062-8.

Cabral J., P. Ribeiro, P. Figueiredo, N. Pimentel and A. Martins [2004]. The Azambuja fault: An active structure located in an intraplate basin with significant seismicity (Lower Tagus Valley, Portugal). Journal of Seismology, 8, 347-362.

Cabral, J., C. Moniz, P. Ribeiro, P. Terrinha and L. Matias [2003] Analysis of seismic reflection data as a toll for the seismotectonic assessment of a low activity intraplate basin-The Lower Tagus Valley (Portugal). Journal of Seismology, 7, 431-447.

Carvalho, J., J. Cabral, R. Gonçalves, L. Torres, and L. Mendes-Victor [2006]. Geophysical methods applied to fault characterization and earthquake potential assessment in the Lower Tagus Valley, Portugal. Tectonophysics, 418, no. 3-4, 277-297.

Carvalho, J., T. Rabeh, F. Carrilho, J. Cabral, and M. Miranda [2008]. Geophysical characterization of the Ota-Vila Franca de Xira-Lisbon-Sesimbra fault zone, Portugal. Geophys. J. Int., 174, 567-584.

Carvalho, J., Ghose, R., Alves, D. and Leote, J. [2016]. Earthquake faulting-related deformation in soil evidenced in S-wave shallow reflection data: field results from Portugal. Geophysics, 81 (5), IM97IM108. doi:10.1190/geo2015-0040.1.

Custódio, S., Lima, V., Vales, D., Cesca, S. and Carrilho, F. [2016]. Imaging active faulting in a region of distributed deformation from the joint clustering of focal mechanisms and hypocentres: application to the Azores - western Mediterranean region. Tectonophysics 676, 70-89. http://dx.doi.org/10.1016/j.tecto.2016.03.013.

Floyd, J.S., J.C. Mutter, A.M. Goodlife, and B. Taylor [2001]. Evidence of fault weakness and fluid flow within an active low-angle normal fault. Nature, 411, 779-783.

García-Mayordomo, J., Insua-Arévalo, J.M., Martínez-Díaz, J.J., Jiménez-Díaz, A., Martín-Banda, R., Martín-Alfageme, S., Álvarez-Gómez, J.A., Rodríguez-Peces, M., Pérez-López, R., Rodríguez-Pascua, M.A., Masana, E., Perea, H., Martín-González, F., Giner-Robles, J., Nemser, E.S., Cabral, J., Compilers, Q.A.F.I. [2012]. The quaternary active faults database of Iberia (QAFI v. 2.0). J. Iber. Geol. 38, 285-302.
Ghose, R. [2012]. A microelectromechanical system digital 3C array seismic cone penetrometer. Geophysics, 77 (3), WA99-WA107, doi: 10.1190/GEO2011-0266.1.

Ghose, R. and J. Goudswaard [2004]. Integrating S-wave seismic reflection data and cone-penetration-test data using a multiangle multiscale approach. Geophysics, 69, no. 2, 440-459, doi: 10.1190/1.1707064.

Ghose, R., J. Carvalho, and A. Loureiro [2013]. Signature of fault zone deformation in near-surface soil visible in shear-wave seismic reflections. Geophysical Research Letters, 40,1-5, doi: 10.1002/grl.50241.

Harris, J.B. [2009]. Hammer-impact SH-wave seismic reflection methods in neotectonic investigations: General observations and case histories from the Mississippi embayment, U.S.A. J. Earth Sci., 20, no. 3, 513-524.

Justo, J.L., and C. Salwa [1998]. The 1531 Lisbon earthquake, Bull. Seismol. Soc. Am., 88, 319-328.

Perea, H., P. Figueiredo, J. Carner, S. Gambini, and K. Boydell [2003]. Paleoseismological data from a new trench across the El Camp Fault (Catalan Coastal Ranges, NE Iberian Peninsula). Ann. Geophys., 46, no. $5,763-774$.

Rockwell, T., J. Fonsa, C. Madden, T. Dawson, L. A. Owe, S. Vilanova, and P. Figueiredo [2009]. Palaeoseismology of the Vilaria Segment of the Manteigas-Bragana Fault in northeastern Portugal, in Palaeoseismology: Historical and Prehistorical Records of Earthquake Ground Effects for Seismic Hazard Assessment, edited by K. Reicherter, A. M. Michetti, and P. G. Silva, vol. 316. The Geological Society, London, Special Publications, 237-258.

Thorbecke, J. and D. Dragannov [2011]. Finite-difference modeling experiments for seismic interferometry. Geophysics, 76 (6), H1-H18.

Vervaeck [2011]. http://earthquake-report.com/2011/02/07/killer-earthquakes-in-portugal-mainland/.

Vilanova, S.P. and Fonseca, J.F.B.D. [2004]. Seismic hazard impact of the Lower Tagus Valley fault zone (SW Iberia). J. Seismol. 8, 331-345.

Vilanova, S.P., Nemser, E., Besana-Ostman, G.M., Bezzeghoud, M., Borges, J.F., Brum da Silveira, A., Cabral, J., Carvalho, J., Cunha, P.P., Dias, R.P., Madeira, J., Lopes, F.C., Oliveira, C.S., Perea, H., García Mayordomo, J., Wong, I., Arvidsson, A., Fonseca, J.F.D.B. [2014]. Incorporating descriptive metadata into seismic source zone models for seismic hazard assessment. Bull. Seismol. Soc. Am. 104, 1212-1229. http://dx.doi.org/10.1785/0120130210.

Wang, Z., I.P. Madlin and E.W. Woolery [2004]. Shallow SH-wave seismic investigation of the Mt. Angel Fault, Northwest Oregon, USA. Tectonophysics, 368 (1-4), 105-117.

Woolery, E.W., R. Street, Z. Wang and J.B. Harris [1993]. Near surface deformation in the New Madrid seismic zone as imaged by high-resolution SH-wave seismic methods. Geophys. Res. Lett., 20 (15), 1615-1618. 